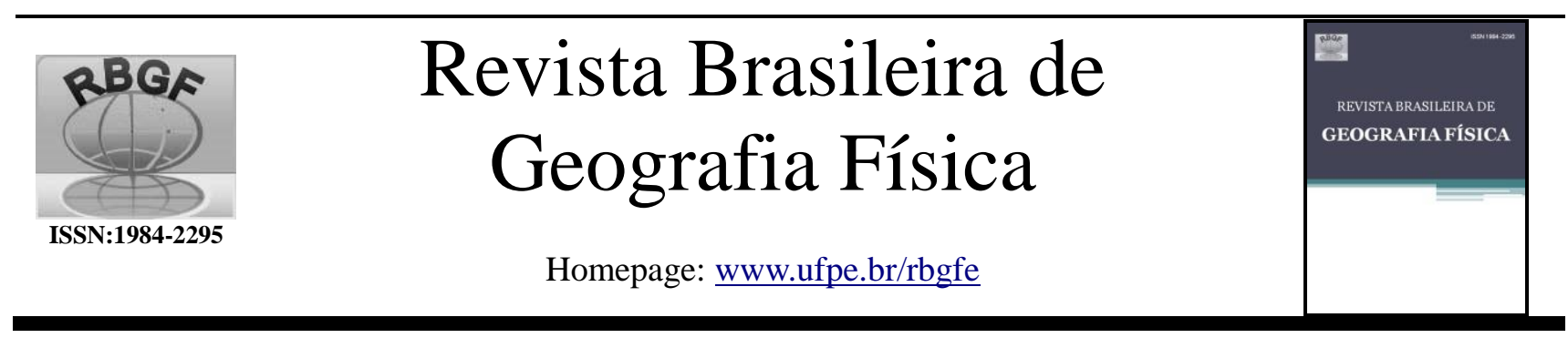

\title{
Técnicas de sensoriamento remoto aplicada análise da concentração de sólidos em suspensão na UHE Foz do Rio Claro - GO
}

\author{
João Batista Pereira Cabral ${ }^{1}$. Waterloo Pereira Filho ${ }^{2}$
}

${ }^{1}$ Professor Doutor, Coordenador do Programa de Pós-Graduação em Geografia, Universidade Federal de Goiás - Regional Jataí, jbcabral2000@yahoo.com.br ${ }^{2}$ Professor Doutor, Docente do Programa de Pós-Graduação em Geografia, Universidade Federal de Santa Maria, waterloopf@gmail.com

Artigo recebido em 23/10/2017 e aceito em 09/07/2018

\section{RESUMO}

A utilização de dados espectrais tem sido utilizado para avaliar e diagnosticar a qualidade das águas em reservatórios a partir de substâncias opticamente ativas. O presente trabalho tem por objetivo avaliar a utilização das técnicas de sensoriamento remoto a partir de métodos de análise derivativa, remoção do contínuo e razão entre bandas para identificar os comprimentos de ondas mais sensíveis em relação à concentração de sólidos em suspensão (CSS). Dados de campo foram coletados em 23 pontos no reservatório de Foz do Rio Claro (GO - Brasil), em dois períodos distintos (seco e chuvoso), utilizando espectrorradiômetro FieldSpec®HandHeld. De acordo com os dados avaliados, verificouse ciclo sazonal bem definido, com maiores valores de reflectância no período de chuva e menores valores de reflectância no período seco. Análise derivativa apresentou resultados significativo, a $99 \%$ ao se correlacionar reflectância e CSS nos períodos seco e chuvoso, sendo considerada a melhor técnica para estimar a CSS em relação ao uso de valores de reflectância e CSS para o reservatório de Foz do Rio Claro.

Palavras-chave: Reflectância, Espectrorradiômetro, Reservatório

\section{Remote sensing techniques for analysis of the concentration of suspended solids in the hydroelectric plant Foz do Rio Claro-Brazil}

\begin{abstract}
A B S T RA C T
The use of spectral data have been used to assess and diagnose the quality of water in reservoirs from optically active substances. This study had as objective evaluate the use of remote sensing techniques from the derivative analysis, continuum removal and right between bands methods to identify the more sensible wavelengths in relations the concentration of suspended solids (CSS). Field data were collected in 23 points in Foz do Rio Claro Reservoir (Brazil), in two distinct stations (dry and wet),using FieldSpec@HandHeld spectrum-radiometer. According to the data assessed there has been seasonal cycle well set with higher reflectance values in the station of rain and lower values in the dry station. Derivative analysis showed significant results in more than $99 \%$ by correlating reflectance and CSS during dry and rainy seasons, being considered the best technique to estimate the CSS regarding the use of reflectance values, for the mouth Foz do Rio Claro reservoir.
\end{abstract}

Keywords: Reflectance, Spectrum-Radiometer, Reservoir.

Parte da pesquisa de Pós-Doutoramento do primeiro autor desenvolvida junto ao programa de Pós-Graduação em Geografia da Universidade Federal de Santa Maria - Brasil. 


\section{Introdução}

O monitoramento da concentração de sólidos em suspensão e vários outros parâmetros limnológicos, como por exemplo a clorofila_ $a$ e a turbidez, em empreendimentos hidráulicos, são de fundamental importância para o gerenciamento da produção de energia, navegação, irrigação, abastecimento doméstico, abastecimento industrial, dessedentação de animais, aquicultura, preservação da flora e da fauna, recreação e lazer, harmonia paisagística e diluição de despejos, além de fornecer informações essenciais sobre 0 processo de assoreamento e eutrofização de corpos hídricos.

Tradicionalmente, o monitoramento de sólidos (suspensão ou arrasto) em rios e reservatórios, aplicados ao estudo da qualidade das águas e assoreamento, é realizado mediante a coleta de amostras da mistura água-sedimento, em pontos amostrais fixos, conhecidos como seções fluviométricas, instaladas, na maioria das vezes, à montante e à jusante dos empreendimentos hidráulicos (Carvalho, 2008).

A falta de dados hidrossedimentológicos/limnológicos é um dos principais problemas enfrentado pela comunidade científica no estudo da distribuição espacial da qualidade das águas e assoreamento. Essa dificuldade ocorre devido à falta de segurança e instalação de instrumentos in situ em corpos hídricos. Outro fator é o alto custo de manutenção e dos levantamentos de campo (Carvalho, 2008; Pinto et al., 2014). Por esse motivo, o baixo número de amostras levantadas em pesquisas hidrossedimentológicas/limnológicas tradicionais, muitas vezes, não são suficientes para uma análise espacial e compreensão do processo de assoreamento/eutrofização em reservatórios, visto que não enfatizam a dinâmica do ambiente e subestimam a variabilidade espacial (Cabral et al., 2013; Pereira, 2015).

Todavia, com o avanço das geotecnologias ocorrido nos últimos anos, o monitoramento da concentração de sólidos em suspensão e de outros parâmetros limnológicos em reservatórios, representa uma alternativa promissora na suplantação dos métodos tradicionais de coleta de parâmetros hidrossedimentológicos/limnológicos e na implantação de sistemas de monitoramento mais eficientes. Entre essas tecnologias, destacam-se os sensores ópticos, a reflexão acústica, a difração a laser, a diferença de pressão e as análises de imagens digitais (Sari, Castro e Kobiyama, 2015).

Desde que dados espectrais medidos com espectrorradiômetros ou registrados em imagens tomadas por sensores instalados em plataformas aéreas ou orbitais tornaram-se disponíveis, trabalhos utilizando esta técnica aplicada a corpos de água continentais têm sido utilizados para correlacionar a resposta espectral com a ocorrência de componentes que indiquem a qualidade da água em reservatórios/rios, demonstrando um potencial para mapear a composição dos corpos hídricos (Novo, Hamson e Curran, 1989; Pereira et al., 2011).

Neste contexto, alguns dos parâmetros hidrossedimentológicos/limnológicos importantes para a compreensão e entendimento da dinâmica dos reservatórios, qualidade das águas e processo de assoreamento, podem ser avaliados por técnicas como a análise derivativa, razão entre bandas e a remoção do contínuo, aplicados ao estudo do comportamento e caracterização espectral e sua relação com a concentração de sólidos em suspensão (Chen, Curran e Hanson, 1992; Wang e Lu, 2010; Gomez, 2015).

A inferência de variáveis relacionadas à qualidade da água, a partir de medidas provenientes de equipamentos espectrorradiométricos, pode ser feita a partir da análise das feições espectrais da radiação solar refletida pelo volume de água, em subsuperfície (Ferreira e Pereira Filho (2009); Lopes et al., 2014; Pereira, 2015). A quantificação da concentração de sólidos em suspensão e sua relação com o comprimento de onda espectral é, portanto, uma das técnicas de mitigação a ser utilizada na prevenção e no controle dos problemas causados pelo transporte e deposição de sólidos.

A escolha do reservatório da Usina Hidrelétrica (UHE) Foz do Rio Claro como objeto de estudo justifica-se devido aos processos antrópicos que ocorrem na bacia do rio Claro, proporcionado pelas áreas urbanas, agrícolas (cultivo da cana-de-açúcar, milho e soja) e de pecuária (criação de gado), proporcionando o despejo de efluentes domésticos e industriais para os cursos d'água, ocasionando alteração na dinâmica dos rios e reservatórios pelo aumento da poluição pontual e difusa que as atividades antrópicas proporcionam, de acordo com as pesquisas desenvolvidas por Cabral et al. (2013), 
Rocha, Cabral e Braga (2014) e Nogueira et al. (2015).

Neste contexto, o presente trabalho teve por objetivo analisar o emprego de técnicas de sensoriamento remoto para mensuração da CSS no reservatório de Foz do Rio Claro (GO). Buscou-se identificar os comprimentos de onda da radiação eletromagnética de maior sensibilidade às concentrações de sólidos em suspensão. As técnicas utilizadas foram: remoção do contínuo, análise derivativa e razão entre bandas.

\section{Material e Métodos}

\section{Área de estudo}

A UHE Foz do Rio Claro encontra-se em funcionamento desde janeiro de 2010. A área de seu reservatório é de 7,69 $\mathrm{km}^{2}$ e seu potencial energético é de 64,8 MW (Figura 1). Sua bacia hidrográfica está situada entre os municípios de São Simão e Caçu, no estado de Goiás, com uma área de influência direta de aproximadamente 151 $\mathrm{Km}^{2}$, ao sul da área do distrito de Itaguaçu (GO), na microrregião de Quirinópolis (GO).

Na região, a média anual de pluviosidade varia entre $1.200 \mathrm{~mm}$ a $1.600 \mathrm{~mm}$, existindo dois períodos distintos de distribuição das chuvas: um período menos chuvoso, considerado seco (que contribui com 10 a $20 \%$ da precipitação anual), com duração de 4 a 5 meses (maio a setembro), sendo que em julho $\mathrm{e}$ agosto $\mathrm{o}$ índice pluviométrico chega a zero (0) $\mathrm{mm}$ e um período chuvoso (outubro a abril), que contribui com $80 \%$ a $90 \%$ da precipitação anual. A temperatura média anual oscila entre $22^{\circ} \mathrm{C}$ e $23^{\circ} \mathrm{C}$ (Mariano; Santos e Scopel, 2003; Lima e Mariano, 2014).

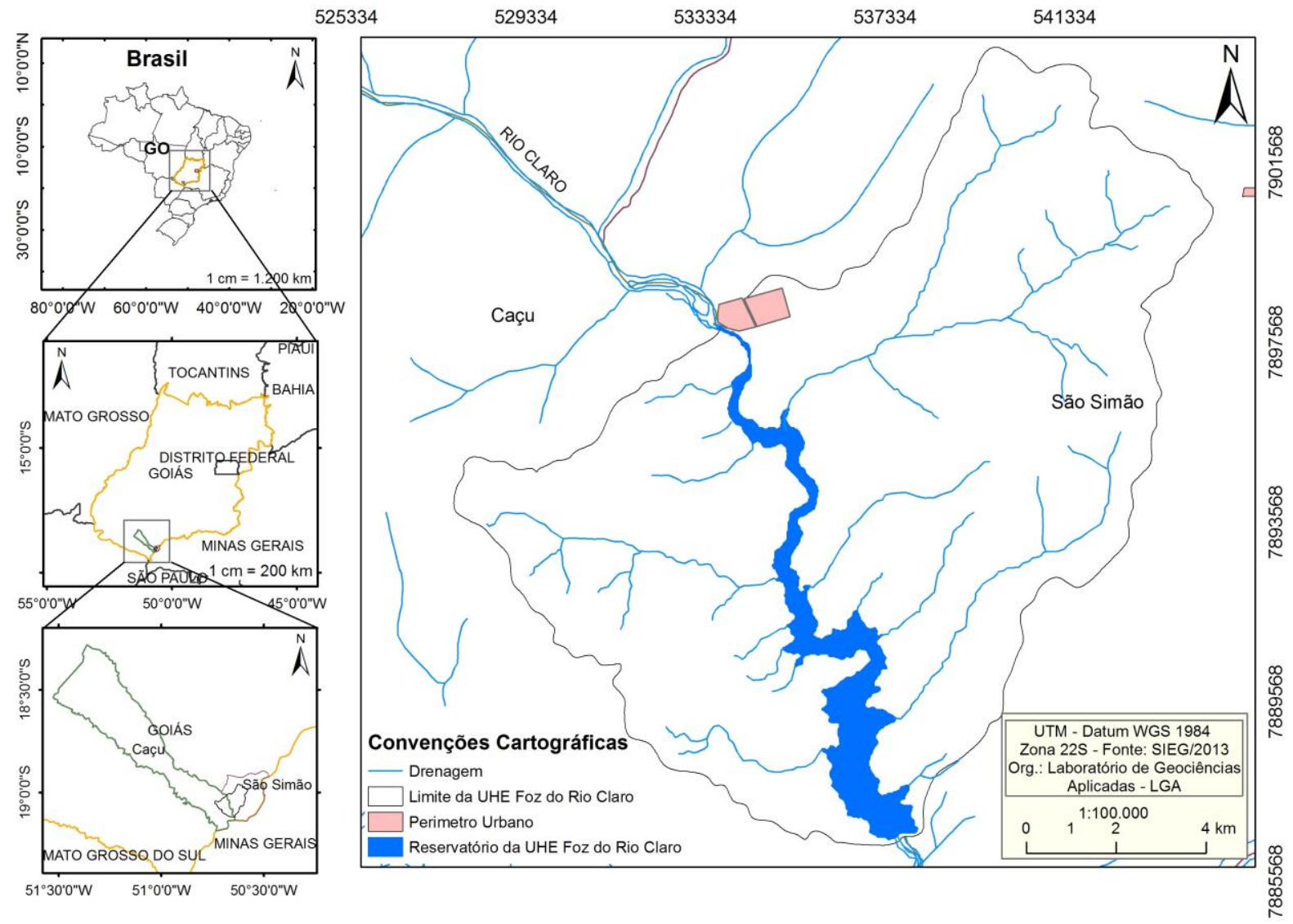

Figura 1: Localização da área de estudo. Fonte: Queiroz Júnior et al., 2013.

Definição dos pontos de amostragens e coleta de dados em campo
Foram definidos 23 pontos de amostragem (obedecendo eqüidistância de $1 \mathrm{~cm}$ na 
escala cartográfica de 1.250.000) no reservatório da UHE de Foz do Rio Claro, de modo a abranger os compartimentos aquáticos que são: seção rio (encontra-se a maior concentração de CSS e pouca transparência da água), seção transição e seção lacustre (encontra-se a menor concentração de CSS e maior transparência da água), conforme a proposta de Kimmel et al. (1990).

As amostras de água foram coletadas nos primeiros $20 \mathrm{~cm}$ de profundidade, correspondendo à camada mais superficial do corpo d'água (epilímnio), no qual tende a ocorrer as maiores temperaturas, o que, juntamente com o aporte de nutrientes, aumenta a produtividade de organismos nas camadas superficiais (Esteves, 1998; Tundisi e Tundisi, 2008). Em cada ponto de amostragem, foram coletados $1.000 \mathrm{ml}$ de água para determinação da concentração de sólidos em suspensão, de acordo os procedimentos previstos em Wetzel e Likens (1991) e APHA (1998).

As concentrações de sólidos em suspensão são determinadas por intermédio da equação1:

$$
\text { Equação1: } C S S=\frac{P 2-P 1}{V} 1000
$$

Onde: CSS $=$ Concentração de sólidos em suspensão $(\mathrm{mg} / \mathrm{L}) ; \mathrm{P} 1$ = peso inicial do filtro $(\mathrm{g})$; P2 = peso do filtro com material coletado após secagem em estufa $(\mathrm{g}) ; \mathrm{V}=$ volume de água utilizado para filtração (L); $1000=$ fator conversão para miligramas.

Os espectros de refletância foram medidos in situ com o auxílio do espectrômetro portátil de campo marca FieldSpec $® H a n d H e l d$, que produz dados na faixa de $325 \mathrm{~nm}$ a $1.075 \mathrm{~nm}$. Para o presente estudo, somente os comprimentos de onda entre $400 \mathrm{~nm}$ e $900 \mathrm{~nm}$ foram utilizados, devido ao alto nível de ruído para comprimentos de onda localizados fora desta faixa, e por que que em água limpa a relação sinal ruído fica comprometida. As reflectâncias foram obtidas de acordo com a proposta de Milton et al (2009) e utilizadas por Wachholz (2011), ângulo azimutal solar de orientação $90^{\circ}$, a uma inclinação de $45^{\circ}$ do equipamento em relação à vertical, e à altura aproximada de $1 \mathrm{~m}$.

As coletas e medições em campo foram realizadas nos dias 28 de julho de 2015 (período seco, pois ocorre um déficit hídrico que é diferença entre a evapotranspiração potencial e a real, visto que em julho e agosto as precipitações são inferiores a $10 \mathrm{~mm}$ mensal) e 06 de fevereiro de 2016 (período chuvoso, pois ocorre um excedente hídrico, diferença entre a precipitação e a evapotranspiração potencial, quando o solo atinge a sua capacidade máxima de retenção de água). As coletas foram realizadas em condições de céu claro em 2015 e de céu claro/nublado em 2016.

Análise das informações dos espectros de refletâncias

Para identificar os comprimentos de onda mais sensíveis em relação à concentração de sólidos em suspensão (CSS), foram utilizadas as seguintes técnicas de análise de espectros: filtragem, métodos de análise derivativa, remoção do contínuo e razão entre bandas.

\section{A) Filtragem - Remoção dos ruídos}

Para remover os ruídos das curvas espectrais, foram utilizados filtros de suavização lineares de média móvel de três pontos. O mesmo foi utilizado por não alterar significativamente a posição das feições $\lambda \max$ ( comprimento de onda máxima) e $\lambda$ min (comprimento de onda mínima) (BREUNING et al., 2007; PEREIRA, 2015).

\section{B) Análise Derivativa}

A técnica de análise derivativa foi realizada de acordo com a proposta de Chen, Curran e Hanson (1992), com intuito de realçar as feições que se destacam na assinatura espectral, tanto em pico de reflectância, como em bandas de absorção. Essa técnica calcula a taxa de mudança da reflectância em relação à taxa de variação em relação ao comprimento de onda.

A formulação matemática para análise derivativa dos espectros de reflectância utilizada nessa pesquisa é apresentada na Equação 2:

Equação 2: $d s=\frac{(\lambda j)-s(\lambda i)}{\Delta \lambda}$

Onde: ds = Derivada Espectral;

$\mathrm{s}=$ Sinal verdadeiro da reflectância $(\lambda \mathrm{j}$ - maior comprimento de onda e $\lambda \mathrm{i}$ - menor comprimento de onda)

$\Delta \lambda=$ Separação entre as bandas adjacentes $(\Delta \lambda=$ $\lambda \mathrm{j}-\lambda \mathrm{i})$, constante. 


\section{C)Remoção do contínuo}

A técnica de remoção do contínuo consiste em remover as feições contínuas dos espectros, onde o contínuo é uma função matemática utilizada para isolar bandas de absorção particulares dos espectros de reflectância, permitindo qualificar a análise espectral (Clark e Rough, 1984).

A formulação matemática para a remoção do contínuo dos espectros de reflectância utilizadas nessa pesquisa é apresentada na Equação 3:

Equação 3: $P C R \lambda,=\frac{\text { POriginal }}{\text { Pcontinuo } \lambda}$

Onde: PCR $\lambda$ é o fator de reflectância direcional cônico com o contínuo removido;

POriginal $\lambda$ é o fator de reflectância direcional cônico original;

Pcontinuod é o espectro do contínuo;

$\mathrm{O} \lambda$ representa o comprimento de onda.

A profundidade de banda "Pd" foi obtida a partir da Equação 4:

Equação 4: $\operatorname{Pd}=(1-\operatorname{PCR} \lambda)$

Onde:Pd é a profundidade de banda;

PCR $\lambda$ é o fator de reflectância direcional cônico com o contínuo removido.

Os valores de reflectância foram normalizados em 1 de tal forma que os pontos dos espectros resultantes fossem ajustados entre $o$ contínuo e os espectros menores que 1 onde ocorrem feições de absorção. Os comprimento de onda selecionados para a realização da remoção de contínuo foram de 460 a $547 \mathrm{~nm}, 597$ a $628 \mathrm{~nm}$ e 701 a $799 \mathrm{~nm}$. Os mesmos foram selecionados a partir de inspeção visual, em função da presença de feições de absorção.

\section{D) Razão entre Bandas}

A técnica de razão de bandas foi utilizada a fim de discriminar sutis diferenças existentes no comportamento espectral de alvos, proporcionando o realce dos mesmos. equação 5:

A razão entre bandas foi obtida a partir da

\section{Equação 5:}

\section{Equação5: $R=P \lambda>P \lambda<$}

Onde:

R é igual a razão entre bandas;

$\mathrm{P} \lambda>$ - reflectância no comprimento de onda maior;

$\mathrm{P} \lambda<$ - reflectância no comprimento de onda menor.

Os comprimento de onda selecionados para a realização da razão entre bandas foram de $490 / 547 \mathrm{~nm}, 505 / 628 \mathrm{~nm}$ e 701/759 nm. Os mesmos foram selecionados a partir de inspeção visual, em função da presença de feições de absorção.

\section{Análise estatística}

Para avaliar o grau de relacionamento entre duas variáveis, foram gerados diagramas de dispersão de Pearson, conforme descrito em Callegari-Jacques (2008). Para avaliar a significância do coeficiente de correlação, utilizou-se o teste de hipótese de Student $(t)$. O valor crítico da distribuição do $t$ das 23 amostras adotado para o nível de significância de $99 \%$ foi de 2,807 .

Uma vez determinada as correlações (r), as mesmas foram classificadas qualitativamente de acordo com a tabela 1 . 
Revista Brasileira de Geografia Física v.11, n.04 (2018) 1526-1541.

Tabela 1 - Avaliação qualitativa do grau de correlação entre as variáveis analisadas

\begin{tabular}{ll}
\hline$R$ & Correlação \\
\hline 0 & Nula \\
$0-0,3$ & Fraca \\
$0,3-0,6$ & Regular \\
$0,6-0,9$ & Forte \\
$0,9-1$ & Muito Forte \\
1 & Plena ou Perfeita \\
\hline
\end{tabular}

\section{Resultados e discussão}

reflectância variou de 0,02 a $0,21 \%$, enquanto que no período chuvoso a variação foi de 0,04 a $0,32 \%$ (Figura 2B).

Dados de Reflectância e CSS

De acordo com os dados de reflectância obtidos, no período seco (Figura 2A) a

A)

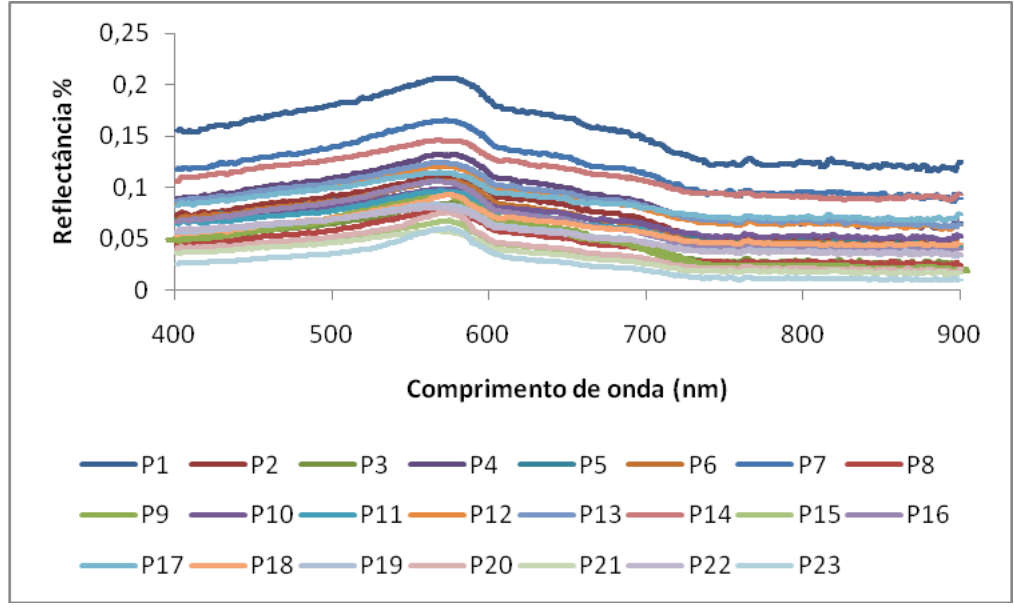

B)

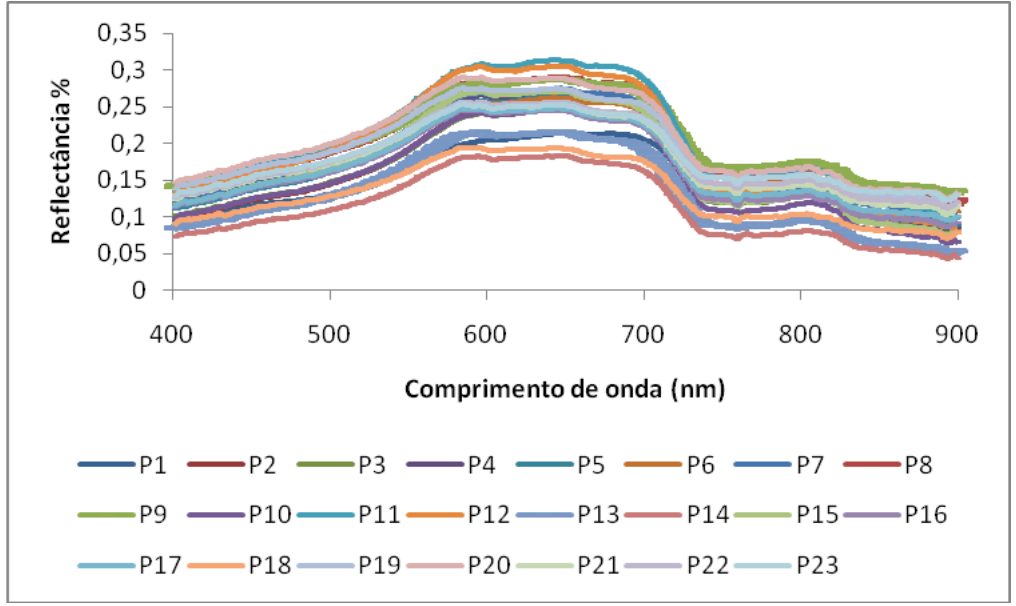

Figura 2 - Curvas de reflectância dos 23 pontos de amostragem nos períodos seco (A) e chuvoso (B). 
No período seco (Figura 2A), pode-se verificar aumento da reflectância entre $400 \mathrm{~nm}$ e $550 \mathrm{~nm}$ (faixa do azul), sendo que o pico máximo de reflectância ocorreu na faixa entre $550 \mathrm{~nm}$ e $590 \mathrm{~nm}$ (faixa do verde), com um decréscimo entre $590 \mathrm{~nm}$ a $900 \mathrm{~nm}$ (Faixa do verde ao infravermelho próximo). No período seco, o máximo de refletância na região do verde pode ser considerado um indicativo da presença de absorção no azul e vermelho que indica a possível presença de fitoplancto.

No período chuvoso (Figura 2B), a alta reflectância foi detectada entre a faixa de 580 a $690 \mathrm{~nm}$ (faixa do Verde e Vermelho), com um decréscimo entre 690 a $820 \mathrm{~nm}$ e um pequeno pico de reflectância entre 800 e $815 \mathrm{~nm}$, que corresponde a uma região de absorção mínima da água pura, e o pico de reflectância pode estar associado a uma menor atenuação da radiação eletromagnética (REM) (Jensen, 2009).
A diferença de reflectância entre os períodos avaliados está associada à matéria inorgânica da CSS. No período seco (Tabela 2), a CSS variou de $0,5 \mathrm{mg} / \mathrm{L}$ a $4,7 \mathrm{mg} / \mathrm{L}$ em todo o reservatório, enquanto que no período chuvoso houve variação de $10,6 \mathrm{mg} / \mathrm{l}$ a $27,3 \mathrm{mg} / \mathrm{L}$, demonstrando que a maior quantidade de sólidos favorece $o$ espalhamento da radiação eletromagnética, aumentando a reflectância no vermelho, pois a resposta espectral em função desse material varia de acordo com sua granulometria, sendo que a presença de silte e areia tende a ter maiores reflectâncias do que aquele constituído por argila (Jensen, 2009; Kirk, 2011).

O espectro do período chuvoso pode ser associado a ambientes dominados por alta concentração de partículas inorgânicas, fato esse comprovado por Barbosa (2005).

Tabela 2 - Estatística descritiva da css

\begin{tabular}{lcr}
\hline Medidas & Período seco & Período Chuvoso \\
Mínimo & 0,5 & 10,6 \\
Máximo & 4,7 & 27,7 \\
Média & 1,12 & 14,36 \\
Desvio Padrão & 1,08 & 4,54 \\
Coeficiente de Variação(CV\%) & 96,31 & 31,65
\end{tabular}

Fonte: Próprio autores

O cruzamento de dados dos valores de CSS (mg/L) e reflectância (\%), a partir da correlação de Pearson, indica que no período seco (Figura $3 \mathrm{~A}$ ) ocorre uma associação que varia de $47 \%$ a $59 \%$ entre os parâmetros estudados, com " $r$ " de 0,59 , no comprimento de onde $593 \mathrm{~nm}$, com $\tau$ (teste de hipótese de Student) igual a 3,40, sendo significativo em mais de $99 \%$. No período chuvoso(Figura 3B), esta associação ficou entre $30 \%$ e $13 \%$, com " $r$ " de - $30 \%$ no comprimento de onda $485 \mathrm{~nm}, \tau$ igual a 1,46 , não sendo significativo para o nível de confiança de $99 \%$. Qualitativamente, o grau de correlação entre as duas variáveis pode ser considerado forte no período seco.
No período seco (Figura 3A), o maior nível de correlação significativa entre CSS e reflectância ocorreu entre os comprimento de onda de $400 \mathrm{~nm}$ a $700 \mathrm{~nm}$, diminuindo em direção à faixa do infravermelho próximo. No período chuvoso (Figura 3B), o maior nível de correlação ocorreu no comprimento de onda de $400 \mathrm{~nm}$ e 500 $\mathrm{nm}$, demonstrando que quanto maior é o comprimento de onda, menor é a absorção da REM.

A partir da análise espacial da CSS e reflectância (Figura 4A a D), nos períodos seco e chuvoso, é possível verificar que a diminuição dos valores de CSS no corpo d'água ocorreu ao longo do eixo longitudinal do reservatório, influenciado, 
possivelmente, pela diminuição de velocidade de escoamento da água, largura do canal e maior profundidade, fato esse também comprovado por Wachholz (2012), para o reservatório de Barra dos
Coqueiros/Caçu e Cabral et al. (2013), para o reservatório de Caçu, ambos instalados à montante da mesma bacia hidrográfica.

A)

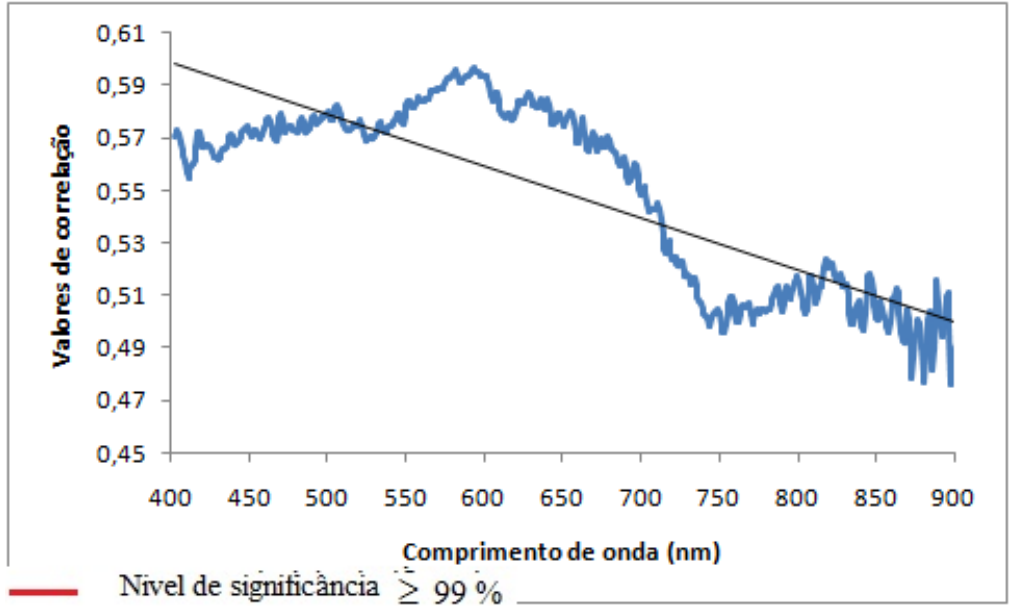

B)

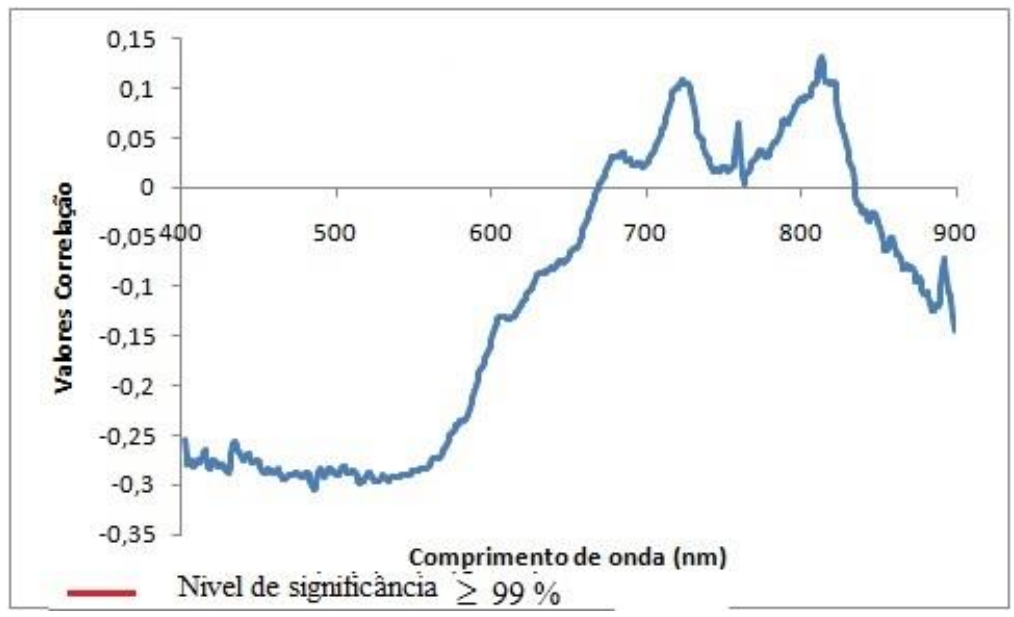

Figura 3: Gráfico de correlação entre CSS e Reflectância: A) período seco e B) chuvoso.

A partir da análise das Figuras 2 a 4, é possível demonstrar que existe um ciclo sazonal bem definido, com altos valores de reflectância no período chuvoso e baixos valores no período seco.

Ao se comparar os valores de reflectância, é possível destacar que existe menor variação no período seco (Figura 4C - correspondente à faixa de $593 \mathrm{~nm}$ ) em relação ao período chuvoso (Figura 4D - correspondente à faixa de $485 \mathrm{~nm}$ ), fato esse que pode ser associado a uma maior homogeneização dos dados de CSS, que variaram de 0 a $5 \mathrm{mg} / \mathrm{L}$, enquanto que no período chuvoso os valores de CSS oscilaram entre 10 e $28 \mathrm{mg} / \mathrm{L}$. $\mathrm{O}$ aumento da concentração de sólidos em suspensão provoca um aumento dos níveis de reflectância, fator este destacado nos estudos desenvolvidos por Curran e Novo (1988), Novo, Hamsom e Curran (1989) e Rudorff et al. (2007). 
Revista Brasileira de Geografia Física v.11, n.04 (2018) 1526-1541.

A)

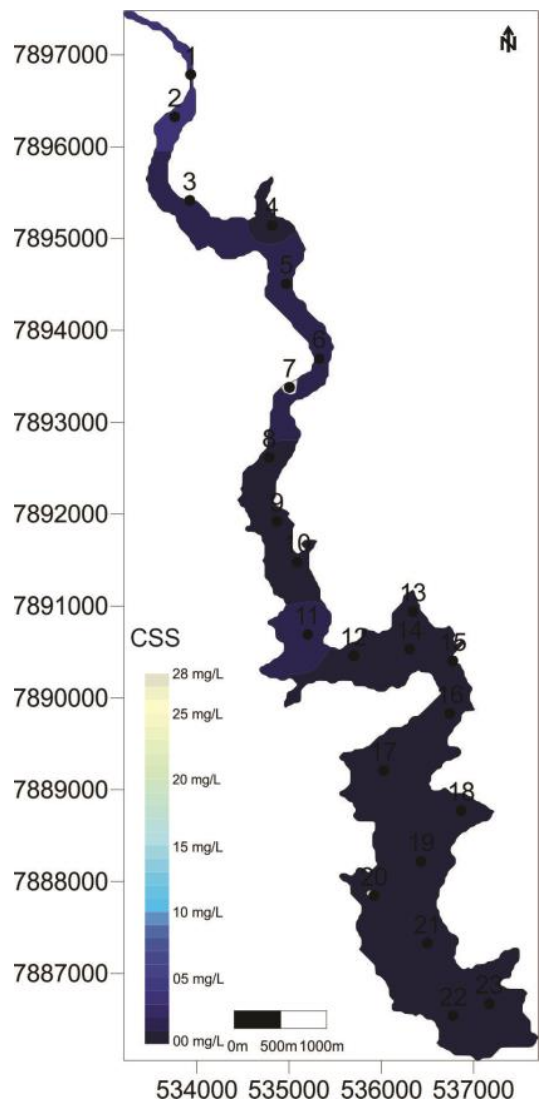

C)

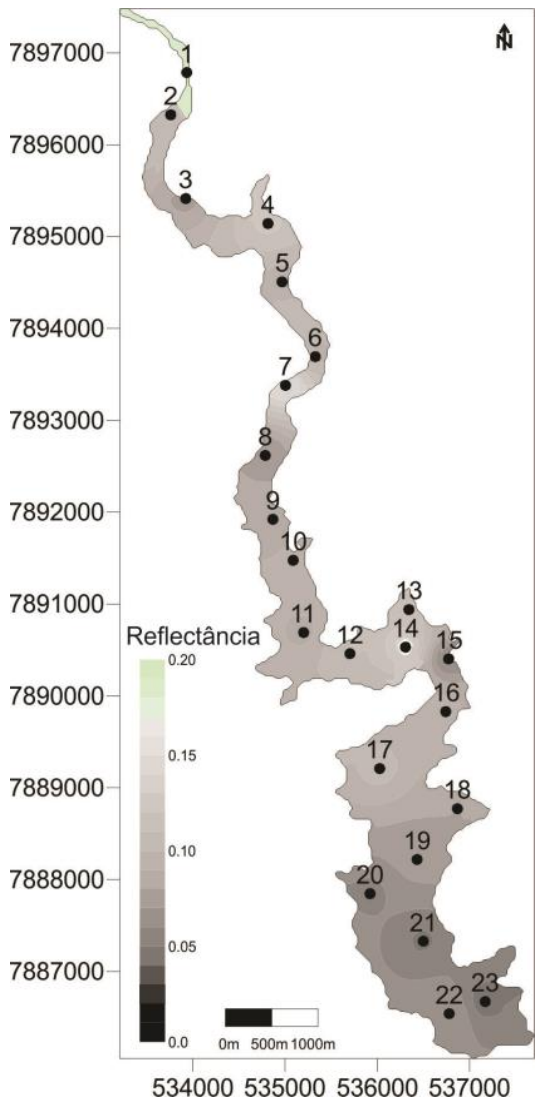

B)

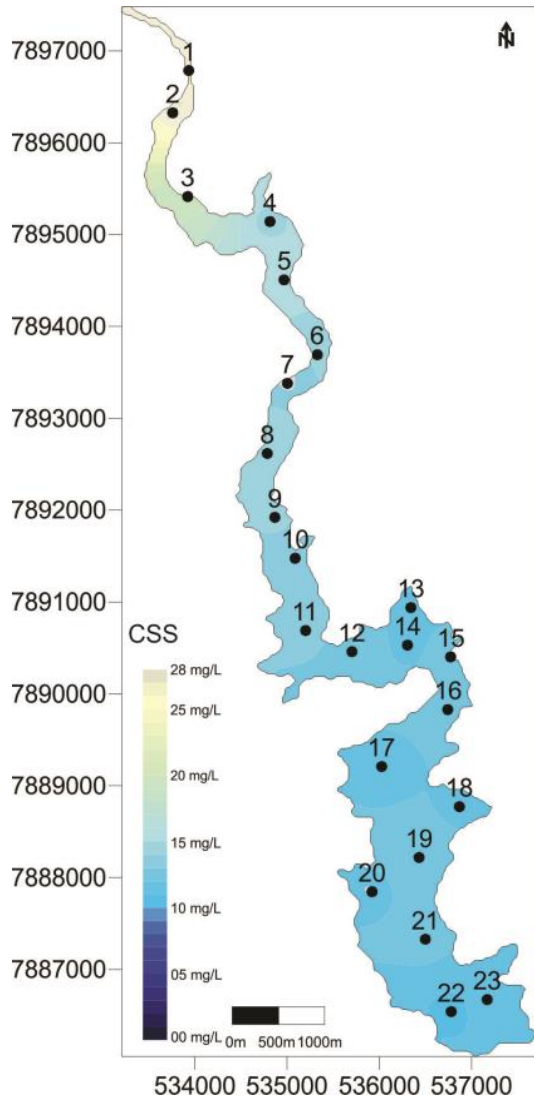

D)

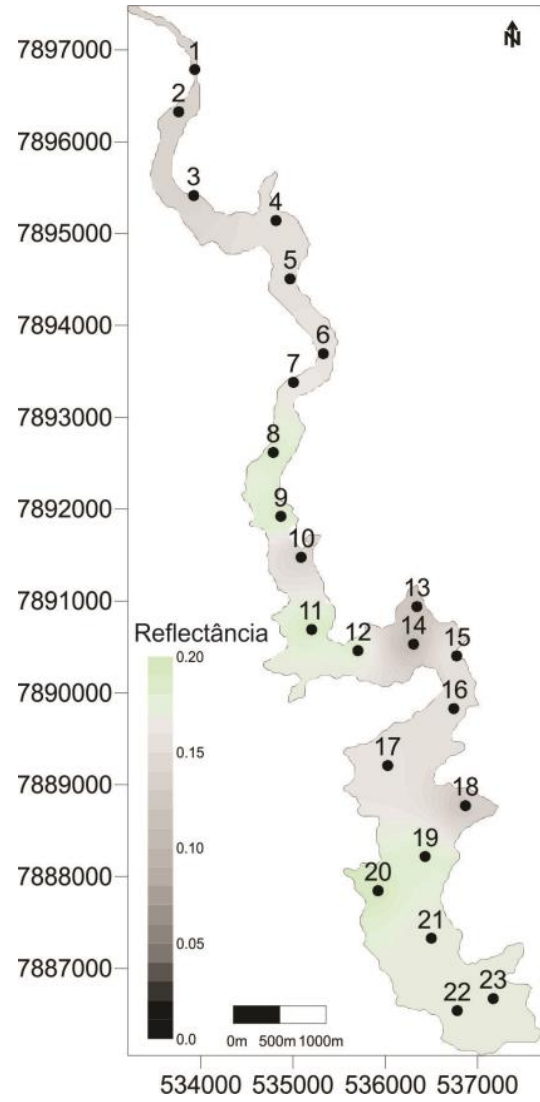

Figura 4) Variação espacial e temporal da CSS e reflectância no reservatório (A e C período seco; B e D período úmido). 


\section{Derivada}

A conversão de espectros em derivadas foi utilizada para acentuar os componentes espectrais menores, que são evidentes nos espectros brutos pela presença de sinais de fundo, melhorando o poder de detectar feições que, de outra maneira, seriam difíceis de identificar. A CSS foi relacionada com a derivada da reflectância em relação ao comprimento de onda, buscando-se melhorar o contraste espectral, aumentando, deste modo, a acurácia da estimativa da informação sobre o alvo (Chen et al., 1992; Zhang et al., 2004; Londe, Novo e Calijuri, 2011).

A partir da análise dos correlogramas, verifica-se que os resultados são distintos. De acordo com os dados avaliados, a análise derivativa realçou a banda de absorção em 604 nm para o período seco (Figura 5A), com uma associação que variou de 0,83 a - 0,87 entre os parâmetros estudados. No período chuvoso (Figura 5B), a análise derivativa realçou a banda de absorção em $601(\mathrm{~nm})$, com uma associação que ficou entre 0,8 e $\quad-0,7$.

A)

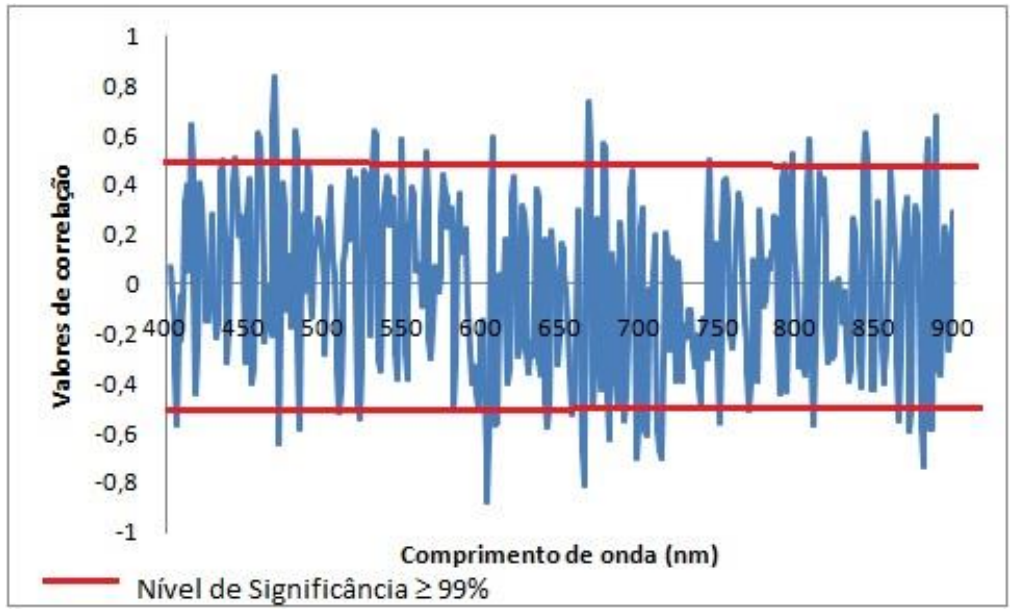

B)

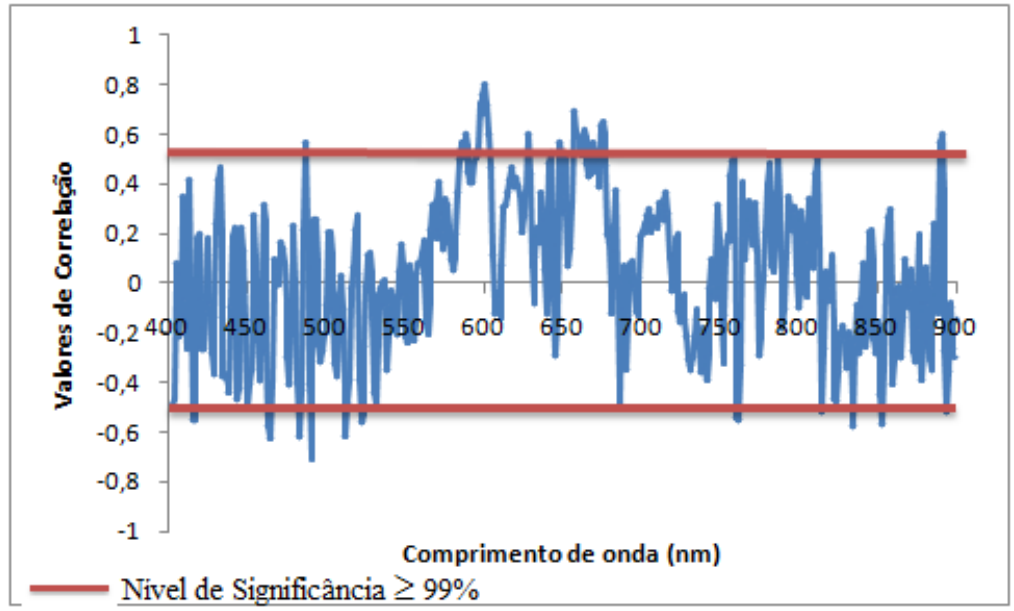

Figura 5: Análise derivativa - Período seco (A) e Período chuvoso (B)

No período seco, o valor de $\tau$ foi de 8,27 , e no período chuvoso (Figura 5B), o valor de $\tau$ foi igual a 6,20, sendo significativo em mais de $99 \%$ em ambos os períodos. Qualitativamente, o grau de correlação entre as duas variáveis pode ser considerado forte.

A principal diferença entre os períodos analisados pode ser observada no período chuvoso, entre a faixa de $600 \mathrm{~nm}$ a $700 \mathrm{~nm}$, que apresenta um aumento nos valores de correlação significativa da CSS e reflectância, com picos de absorção e reflectância. Os picos de reflectância podem ser associados a maior concentração de sólidos suspensos, propiciada pelo aumento dos índices de precipitação na bacia. As feições de absorção detectadas em $610 \mathrm{~nm}$ podem ser relacionadas à possível presença da ficocianina, 
pigmento acessório das cianobactérias, enquanto que em $685 \mathrm{~nm}$ é característico do pigmento fotossintético Chl-a, que absorve fortemente neste comprimento de onda para a realização da fotossíntese (Barbosa, 2005; Kirk, 2011).

De acordo com os dados de chuva obtidos junto aos dois posto pluviométricos instalados na bacia, a precipitação acumulada entre os dias 30/01/2016 e 06/02/2016, no posto 1 (localizado na entrada do reservatório), foi de $181 \mathrm{~mm}$. No posto 2 , que é localizado próximo ao barramento do reservatório, a precipitação acumulada foi de $114 \mathrm{~mm}$. No período seco, não ocorreu evento de precipitação nos 7 dias antecedentes e na data da coleta. A precipitação influencia no tamanho dos sólidos inorgânicos que adentram aos reservatórios, não sendo distribuídos uniformemente, alterando a cor da água (Carvalho, 2008; Cabral et al., 2010; Pinto et al., 2014) e a concentração de sólidos suspensos, implicando no aumento da reflectância entre 590 $\mathrm{nm}$ e $730 \mathrm{~nm}$, em função do espalhamento pelas partículas (Rundquist, 1996; Novo, 2001; Cai, Tang e Li, 2015).

\section{Remoção do Contínuo}

O método de remoção do contínuo espectral foi aplicado às curvas espectrais dos 23 pontos amostrais, tomados "in situ". As feições de absorção adotadas para a aplicação da remoção do contínuo foram aquelas mais acentuadas, observadas para os espectros suavizados, correspondentes aos intervalos de comprimentos de onda: de $460 \mathrm{~nm} / 547 \mathrm{~nm}$; $597 \mathrm{~nm} / 628 \mathrm{~nm}$ e $701 \mathrm{~nm} / 799 \mathrm{~nm}$. As curvas espectrais com o contínuo removido são apresentadas na Figura 6 (de A a F), sendo apresentadas, como exemplo, as curvas dos pontos 1,11 e 20 , que se encontram localizadas nos setores rio, transição e lacustre, de acordo com a proposta de Kimmel, Lind e Paulson (1990). A escolha dessas amostras como exemplo deve-se também ao fator de diminuição da CSS no sentido do perfil longitudinal do reservatório (maior concentração no ponto $1 \mathrm{e}$ menor concentração no ponto 20 ).

Ao se avaliar o comportamento dos espectros, é possível perceber que não há um padrão no comportamento dos pontos para os conjuntos analisados. Os ruídos destacam-se, principalmente, na faixa entre $460 \mathrm{~nm} / 547 \mathrm{~nm}$ (Figuras A e B), nos períodos seco e úmido, e em $701 \mathrm{~nm} / 799 \mathrm{~nm}$ (Figura E) para período seco, embora as curvas tenham sido suavizadas, o que leva a crer que a variabilidade nos espectros pode estar relacionada à influência do horário da coleta e iluminação, fato este também detectado por Pereira (2015), no reservatório de ItupararangaSP.

De modo geral, ocorre uma variabilidade no parâmetro profundidade de banda para o conjunto de pontos analisado. Ainda conforme a figura 6 (A até F), os pontos P20 (período seco) e P11 (período chuvoso) apresentaram maior absorção. O P1 foi o que apresentou menor absorção dentre todo o conjunto em ambos os períodos, fato esse que pode ser associado ao maior valor de CSS em ambos os períodos, pois este encontra-se no setor rio, local em que ocorre, segundo Nogueira et al. (2015), a maior velocidade de escoamento da água, maior vazão e carreamento de sólidos suspensos nesse reservatório.

As análises de correlação entre os parâmetros das bandas de absorção do contínuo removido (profundidade de banda) e a CSS são apresentadas na tabela 3 .

A partir da análise dos dados da tabela 3, é possível concluir que no período seco não ocorre uma associação significativa entre os parâmetros avaliados, pois a concentração de CSS pode ser considerada baixa, fato esse também constatado por Breuning et al. (2007), Molisani et al. (2013) e Cabral et al. (2013) para os reservatórios de Rodolfo Costa e Silva, Castanhão e Caçu. O cálculo para o coeficiente de correlação entre a profundidade das bandas de absorção com a CSS apresentou resultados não significativos entre $460 \mathrm{~nm}$ a $547 \mathrm{~nm}$ e $701 \mathrm{~nm}$ a $-799 \mathrm{~nm}$. A baixa correlação obtida pode ser atribuída à baixa variância da CSS.

No período chuvoso, somente a faixa entre $597(\mathrm{~nm})$ e $628(\mathrm{~nm})$ apresenta um resultado significativo com " $\boldsymbol{R}^{2 "}$ de 0,400 , com $\tau$ igual a 3,74 , sendo significativo a 99\%. Qualitativamente, o grau de correlação entre as duas variáveis pode ser considerado forte. 
Período seco

A)

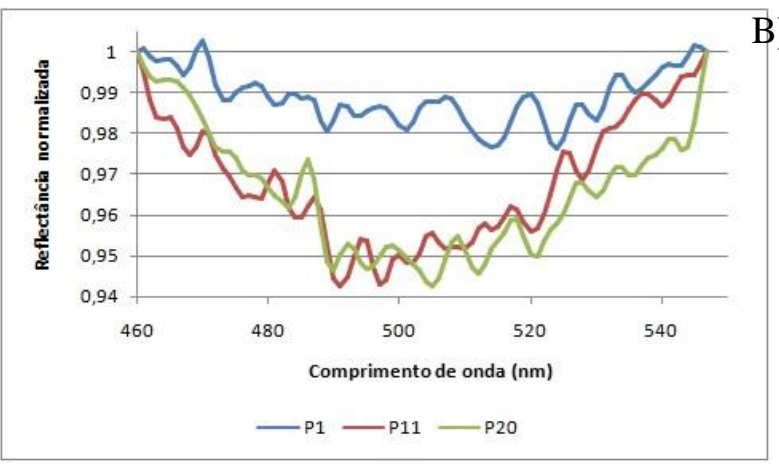

C)

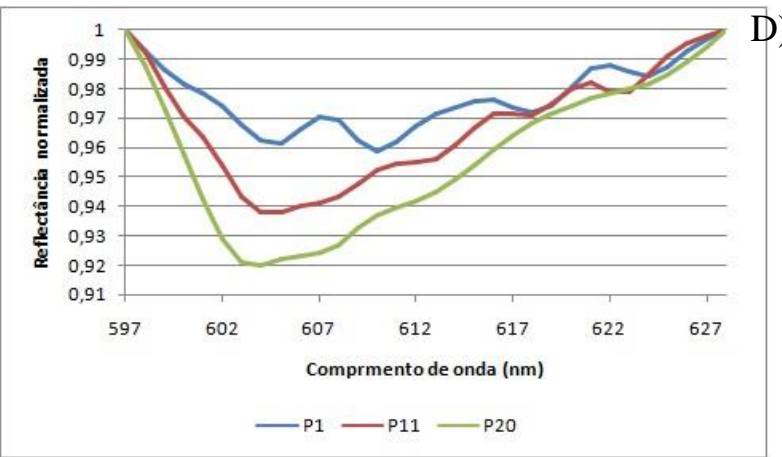

E)

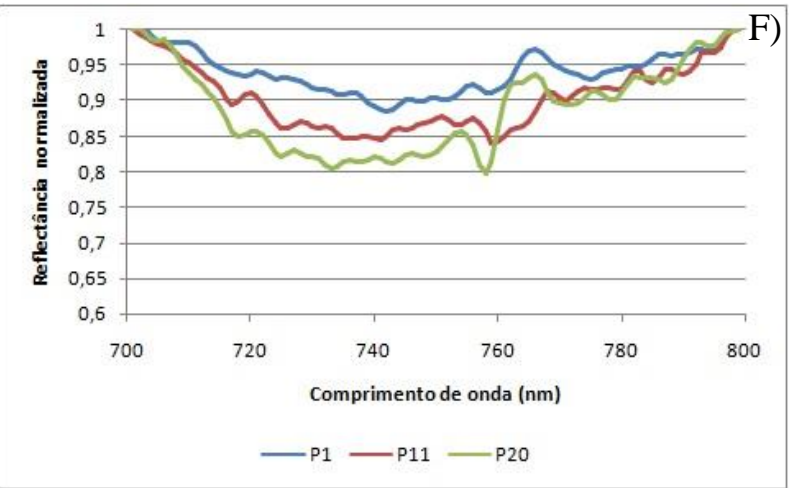

Período úmido

B)

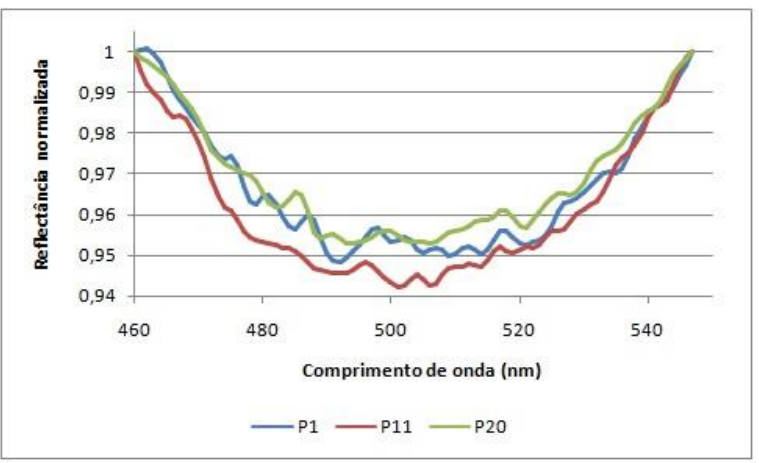

D)
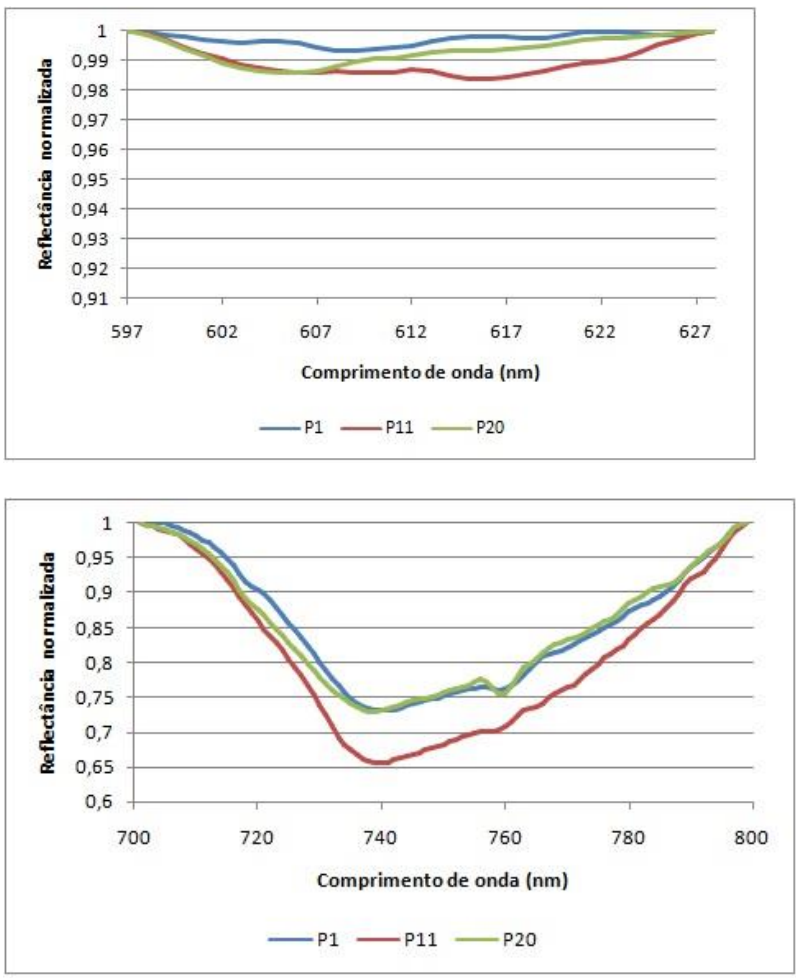

Figura 6 - Gráficos com espectros de reflectância após a remoção do contínuo

Tabela 3: dados estatísticos referentes à remoção do contínuo

\begin{tabular}{|c|c|c|c|c|c|c|}
\hline \multirow[t]{2}{*}{ Período } & \multicolumn{2}{|c|}{$460-547$} & \multicolumn{2}{|c|}{$597-628$} & \multicolumn{2}{|c|}{ 701-799 } \\
\hline & $R^{2}$ & $\mathbf{T}$ & $\overline{R^{2}}$ & $\mathbf{T}$ & $R^{2}$ & $\mathbf{T}$ \\
\hline Seco & 0,064 & 1,20 & 0,040 & 0,94 & 0,027 & 0,10 \\
\hline Úmido & 0,001 & 0,15 & 0,400 & 3,74 & 0,001 & 0,13 \\
\hline
\end{tabular}

$R^{2}$ : Coeficiente de determinação; $\boldsymbol{\tau}$ : teste de hipótese de Student. Fonte: Próprios autores. 


\section{Razão entre bandas}

A razão entre bandas foi realizada para os dados de reflectância e correlacionadas com os valores de CSS, considerando todo o conjunto de dados. A partir da definição de alguns intervalos espectrais que melhor caracterizaram os componentes do corpo d'água, foram selecionadas (análise visual) três faixa do espectro que apresentaram uma grande absorção da radiação, sendo selecionadas as faixas entre 490/547, 605/628 e 701/759.

As maiores correlações significativas (Tabela 4) foram observadas para o intervalo da feição de absorção de $605 \mathrm{~nm}$ e pico de reflectância em $628 \mathrm{~nm}$, pois a alta concentração de CSS faz a reflectância deslocar-se para os comprimentos de ondas maiores e infravermelho próximo, fato esse verificado por Ruddorff et al. (2007), Martinez et al. (2009) e Pinto et al. (2014) para águas continentais.

A correlação significativa mais forte foi com a razão de bandas do vermelho. Nota-se que a razão $605 \mathrm{~nm} / 628 \mathrm{~nm}$ é mais pronunciada do que a $490 \mathrm{~nm} / 547 \mathrm{~nm}$ e $701 \mathrm{~nm} / 759 \mathrm{~nm}$ para o conjunto de dados em questão. Este quadro indica que quanto maior a concentração de CSS, mais pronunciada é a variação da reflectância entre estes dois comprimentos de onda. Assim, o efeito do espalhamento da CSS, responsável pelo aumento da reflectância em $628 \mathrm{~nm}$, é menos pronunciado.

Tabela 4: dados estatísticos referentes à razão de bandas

\begin{tabular}{lllllll}
\hline Período & $490-547$ & \multicolumn{3}{c}{$605 / 628$} & $701-759$ & \\
\cline { 2 - 7 } & $\boldsymbol{R}^{2}$ & $\mathbf{T}$ & $\boldsymbol{R}^{2}$ & $\mathbf{T}$ & $\boldsymbol{R}^{2}$ & $\mathbf{T}$ \\
Seco & 0,099 & 1,52 & 0,101 & 1,54 & 0,027 & 0,77 \\
Úmido & 0,005 & 0,33 & 0,440 & 4,06 & 0,022 & $-1,06$ \\
\hline
\end{tabular}

$R^{2}$ : Coeficiente de determinação; $\tau$ : teste de hipótese de Student.

A não existência de correlações significativas com as razões de banda entre 490547 e 701-759 corrobora com a premissa da influência da Chl-a na CSS e no comportamento espectral da água do reservatório, pois, conforme Dekker (1993) destaca, a razão espectral entre $560 / 520 \mathrm{~nm}$ é uma das mais indicada para a estimativa de sólidos em suspensão. Jensen (2009) destaca que os comprimentos de onda do visível entre 580-690 $\mathrm{nm}$ podem fornecer informações sobre o tipo de sólidos em suspensão no corpo d'água, enquanto que na faixa do infravermelho próximo podem ser úteis para determinar a quantidade de sólidos em suspensão, sendo os constituintes predominantes no corpo d'água. A matéria orgânica age como partículas espalhadoras e apresentam maior capacidade de absorção da radiação, enquanto a matéria inorgânica age preferencialmente como partículas espalhadoras da radiação (CHEN et al., 1992).

A razão entre bandas apresentou um valor de " $r$ " menor do que a análise derivativa. Pode-se assumir, portanto, que a análise que melhor explica a variação quantitativa da CSS para este conjunto de dados é a razão $605 \mathrm{~nm} / 628 \mathrm{~nm}$.

\section{Conclusões}

- De acordo com a resposta espectral das amostras obtidas para o reservatório $\mathrm{Foz}$ do Rio Claro, o ciclo sazonal pode ser considerado bem definido, com maiores valores de reflectância no período chuvoso e menores valores de reflectância no período seco. As melhores respostas espectrais a partir da análise de correlação da reflectância e CSS para o reservatório foram obtidas no comprimento de onda de $593 \mathrm{~nm}$ no período seco e $485 \mathrm{~nm}$ no período chuvoso.

- As técnicas de Remoção de Contínuo e Razão entre Bandas apresentaram correlações classificadas qualitativamente como fortes para os valores de reflectância e CSS, sendo significativas a 99\% no período chuvoso. 
- A análise derivativa apresentou resultados significativos em mais de $99 \%$ ao se correlacionar reflectância e CSS nos períodos seco e chuvoso, sendo considerada a melhor técnica para estimar a concentração de sólidos em suspensão em relação ao uso de valores de reflectância, para o reservatório de Foz do Rio Claro.

- Os dados de reflectância podem ser utilizados como uma solução alternativa para monitorar e compreender a distribuição da concentração de sólidos em suspensão no reservatórios da UHE Foz do Rio Claro, indicando que o espectrorradiômetro é uma ferramenta auxiliar importante para o estudo da composição da água do reservatórios.

\section{Agradecimentos}

À Fundação de Amparo à Pesquisa do Estado de Goiás - FAPEG e à Coordenação de Aperfeiçoamento de Pessoal de Nível Superior CAPES pela concessão da bolsa de PósDoutoramento junto ao programa de PósGraduação em Geografia da Universidade Federal de Santa Maria (UFSM)/ Instituto Nacional de Pesquisas Espaciais - Centro Sul (INPE-CRS).

\section{Referências}

American Public Health Association (APHA); AWWA; WEF. 1998. Standard methods for the examination of water and wastewater. 20. ed. Washington: APHA. $1085 \mathrm{p}$.

Barbosa, C. C. F. 2005. Sensoriamento remoto da dinâmica da circulação da água do sistema planície de Curuai/Rio Amazonas. Tese (Doutorado em Sensoriamento Remoto). São José dos Campos, INPE.

Breuning, F. M.; Wachholz, F.; Pereira Filho,W.; Rudorff, C. M. 2007. Análise das propriedades ópticas da água do reservatório Rodolfo Costa e Silva - Itaara, RS, Brasil, usando dados espectrais de campo e imagens orbitais multiespectrais. Revista Ambiente \& Água 2, n2. Disponível: http://www.ambiagua.net/seer/index.php/ambiagua/article/vie w/28/pdf_267.Acesso: 18 jul. 16.
Cabral, J. B. P.; Wachholz, F.; Becegato, V. A.; Nascimento, E. S. 2013. Diagnóstico Hidrossedimentológico do Reservatório da UHE Caçu - GO. Geofocus 13, 25-37. Disponível:http://www.geofocus.org/index.ph p/geofocusarticle/view/276. Acesso: 5 maio. 14.

Cai, I.; Tang, D. L.; LI, C. Y. 2015. An investigation os spatial of suspended sediment concentration induced by a bay bridge based on Landsat TM and OLI data, Advance in Space Research. n.56. 293-303. Disponível:https://doi.org/10.1016/j.asr.2015. 04.015 Acesso: 4 jul.17.

Callegari-Jacques, S. M. 2008. Bioestatística: princípios e aplicações. Porto Alegre: Artmed. 654p.

Carvalho, N. O. Hidrossedimentologia prática. 2008. 2. ed. Rio de Janeiro: Editora Interciências Ltda. 600p.

Clark, R.N.; Roush, T.L. 1984. Reflectance spectroscopy: quantitative analysis techniques for remote sensing applications. Journal of Geophysical Research 89, nB7, 6329-6340, July $10 . \quad$ Disponível: https://doi.org/10.1029/JB089iB07p06329.

Acesso: 5 jul. 2017.

Chen, Z.; Curran, P. J.; Hanson, J. D. 1992. Derivative refrectance spectroscopy to estimate suspended sediment concentration. Remote Sensing of Enviromment 40. 67-77. Disponível: https://doi.org/10.1016/00344257(92)90127-6. Acesso: 5 jul. 2017.

Curran, P. J; Novo, E. M. M. 1988. The relationship between suspended sediment concentration and remotely sensed spectral radiance: a review. Journal of Coastal Research, n4, 351-368.

Dekker, A. G. 1993. Detection of optical water quality parameters for eutrophic waters by high resolution remote sensing. Tese $(\mathrm{PhD}$ theses). Free University, Amsterdan.

Esteves, F. A. 1998. Fundamentos de limnologia. Rio de Janeiro: Editora Interciência.

Ferreira, A. B.; Pereira Filho, W. 2009. Avaliação da reflectância espectral de corpos d'água em Santa Maria-RS, por meio de espectrorradiometria de campo. Geoambiente 
Revista Brasileira de Geografia Física v.11, n.04 (2018) 1526-1541.

On-line, n13, 194-207. Disponível: http://dx.doi.org/10.5216/rev.\%20geoambie.v 0i13.25996 .Acesso: 6 jul. 2017.

Gomez, R. A. 2015. Análisis espectral del Lago de Guadalupe, medianteimágenes de satélite y datos in situ. Investigaciones Geográficas. n86. 15-24. Disponível: http://dx.doi.org/10.14350/rig.42338. Acesso 5 jul. 2017.

Jensen, J. R. 2009. Sensoriamento remoto do ambiente: uma perspectiva em recursos terrestres. 2. ed. São José dos Campos: Parêntese. 598p.

Kirk, J. T. O. 2011. Light and photosynthesis in aquatic ecosystems. 3ed. New York: Cambridge University Press. 649p.

Kimmel, B. L; Lind; O. T. Paulson, J. L. 1990. Reservoir Primary Production. In: Thorton, K.W; Kimmel, B. L.; Payne, F. E. Reservoir limnology: ecological perspectives. New York: John Wiley and sons. 246p.

Lima, A. M.; Mariano, Z. F. 2014. Análise microclimática no interior e fora das florestas estacionais semidiciduais na área da bacia da usina hidrelétrica de Caçu - GO. Revista do Departamento de Geografia 27, 67-87. Disponível:http://dx.doi.org/10.11606/rdg.v2 7i0.444. Acesso: 8 jan. 2015.

Lopes, F. B.; Barbosa, C. C. F.; Novo, E. M. L. M.; Andrade, E,M.; Chaves, L. C. G. 2014. Modelagem da qualidade das águas a partir de sensoriamento remoto hiperespectral. Revista Brasileira de Engenharia Agrícola e Ambiental 18. S13-19. Disponível: http://www.agriambi.com.br/revista/v18ns/v1 8nsa03.pdf. Acesso:8 jul. 2017.

Londe, L. R; Novo, E. M. L; Calijuri, M. C. 2011. Aplicação de técnicas de sensoriamento remoto ao estudo do fitoplâncton de águas interiores. In: Alcântara, E. H; Novo, E. M. L. de M.; STECH, J. L. Novas tecnologias para o monitoramento e estudo de reservatórios hidrelétricos e grandes lagos. Rio de Janeiro: Parêntese. 254p.

Mariano, Z. F.; Santos, M. J. Z.; Scopel, I. 2003. Variabilidade e tendência climática da região do Sudoeste de Goiás e sua relação com a cultura da soja. In: Seminário de PósGraduação em Geografia da UNESP, Rio
Claro: Universidade Estadual Paulista, v. 1. 596-616.

Martinez, J. M.; Guyot, J. L., Filizola, N., Sondag, F. 2009. Increase in suspended sediment discharge of the Amazon River assessed by monitoring network and satellite data. Catena $79 . \quad 257-264 . \quad$ Disponível: http://dx.doi.org/10.1016/j.catena.2009.05.01 1. Acesso: 6 jul. 2017.

Mollisani, M. M.; Becker, H.; Barroso, H. S.; Hijo, C. A. G.; Monte, T. M.; Vasconcellos, G. H.; Lacerda, L.D. 2013. The influence of Castanhão reservoir on nutrient and suspended matter transport during rainy season in the Jaguaribe river (CE, Brazil). Brazilian Journal Biology. v73. n1. 115-123. Disponível:http://www.scielo.br/pdf/bjb/v73 n1/13.pdf Acesso: 6 jul. 2017.

Milton, E. J. Principles of Field Spectroscopy. 1993. International Journal of Remote Sensing $\quad 8, \quad \mathrm{n} 12, \quad 1807-1827$. Disponível:https://doi.org/10.1080/01431168 708954818Acesso: 30 jun.2017.

Nogueira, P. F.; Cabral, J. B. P.; Oliveira, S. F.; Rocha, I. R. 2015. Eutrofização no reservatório da UHE Foz do Rio Claro (GO). Revista do Departamento de Geografia 30, 19-33.Disponível: http://dx.doi.org/10.11606/rdg.v30i0.90090. Acesso: 15 nov. 2016.

Novo, E. M. L. M.; Hamsom, J. D.; Curran, P. J. 1989. The effect of sediment type on the relationship between reflectance and suspended sediment concentrations. International Journal of Remote Sensing.10,,1283-1289. Disponível: https://doi.org/10.1080/01431168908903967. Acesso: 5 jul.2017

Novo, E. M. L. de M. 2001. Comportamento Espectral da Água. In: Meneses, P. R., Madeira Netto, J. da S. (Orgs.). Sensoriamento remoto: reflectância de alvos naturais. Brasília: Universidade de Brasília.

Pereira. A.C.F. 2015. Water Quality Reserch: Spectral Variability of the water body analysis to defini a sampling scheme. Brazilian Journal of Cartography 67. n5 Special Issue 27th ICC. 1017-1024. Disponível:http://www.lsie.unb.br/rbc/index. 
php/rbc/article/view/1309/848. Acesso: 10 jul.2017.

Pereira, A. C. F.; Galo, M. L. B. T.; Velini, E. D. 2015. Inferência da transparência da água reservatório de Itupararanga/ SP, a partir de imagens multiespectrais IKONOS e espectrorradiometria de campo. Revista Brasileira de Cartografia 1, n.63. 179-190. Disponível:http://www.lsie.unb.br/rbc/index. php/rbc/article/view/370/362. Acesso: 10 jul.2017.

Pinto. C. E. T; Menezes P. H. B. J.; Martinez, J.M; Roig, H. L. Villar, R. A. E. 2014. Uso de imagens MODIS no monitoramento do fluxo de sedimentos no reservatório de Três Marias. In: Revista Brasileira de Engenharia Agrícola e Ambiental 18, n5.. 507-516. Disponível:http://www.agriambi.com.br/revis ta/v18n05/v18n05a07.pdf. Acesso: 6 jul. 2017.

Queiroz Junior. V. S.; Cabral, J. B. P.; Rocha, I. R; Barcelos, A. A. 2014. Uso de geotecnologias na caracterização ambiental da bacia da UHE Foz do Rio Claro (GO). Geofocus. n15. 193212.

Disponível: http://www.geofocus.org/index.php/geofocus/ article/view/413. Acesso: 7 jul. 2017.

Rocha, H. M.; Cabral, J. B. P.; Braga, C. C. 2014. Avaliação Espaço-Temporal das Águas dos Afluentes do Reservatório da UHE Barra dos Coqueiros/Goiás. Revista Brasileira de Recursos Hídricos 19, n1. 131-142. Disponível:http://dx.doi.org/10.21168/rbrh.v 19n1.p131-142. Acesso: 18 nov 2016.

Rudorff, C. M.; Novo, E. M. L. M.; Galvão, L. S.; Filho, W. P. 2007. Análise derivativa de dados hiperespectrais medidos em nível de campo e orbital para caracterizar a composição de águas opticamente complexas na Amazônia. Acta Amazônica 37, n2. 279290.Disponível:http://dx.doi.org/10.1590/S00 44-59672007000200014. Acesso: 7 jul. 2017.
Rundquist, D. C.; Han, L.; Schalles, J. F.; Peak, J. 1996. Remote measurement of algal chlorophyll in surface waters: the case for the first derivative of reflectance near $690 \mathrm{~nm}$. Photogrammetric Engineering \& Remote Sensing, 62, n2. 195-200. Disponível: https://www.researchgate.net/publication/265 108491_Remote_Measurement_of_Algal_Ch lorophyll_in_Surface_Waters_The_Case_for _the_First_Derivative_of_Reflectance_Near_ 690_nm. Acesso: 3 jun. 2017.

Sari, V; Castro, M. R; Kobiyama, M. 2015. Estimativa da concentração de sedimentos suspensos com sensores ópticos: revisão. Revista Brasileira de Recursos Hídricos 20, n4. 816 - 836. Disponível: http://dx.doi.org/10.21168/rbrh.v20n4.p816836 Acesso: 5 jun. 2017.

Tundisi, J. G.; Matsumura Tundisi, T. 2008. Limnologia. São Paulo: Oficina de Textos. 632p.

Wachholz, F. 2011. Influência da bacia hidrográfica e características espaçotemporais devariáveislimnológicas sobre reservatórios no Rio Jacuí-RS. Tese (Doutorado em Geografia) Rio Claro. Universidade Estadual Paulista - Unesp Campus Rio Claro,

Wachholz, F. 2012. Alterações espectrais nas imagens de satélite nos reservatórios das Usinas Hidrelétricas Caçu e Barra dos Coqueiros-GO. Revista Geonorte, v. 3, n 5. 1170-1179.

Disponível: http://www.periodicos.ufam.edu.br/revistageonorte/article/view/2179. Acesso: 10 mai. 2016.

Wang, J. J.; Lu, X. X. 2010. Estimation of suspended sediment concentrations using Terra MODIS: An example from the Lower Yangtze River, China. Science of the Total Environment 408. 1131-1138. Disponível: Acesso:https://doi.org/10.1016/j.scitotenv.20 09.11.057. 8 jul. 2017.

Wetzel, R. G.; Likens, G. E. 1991. Limnological analyses. 2 ed. New York: Springer- Verlag. $391 \mathrm{p}$. 